\title{
EDITORS’ PREFACE
}

I am very pleased to present the second issue of Politeja. The Journal of the Faculty of International and Political Studies of the Jagiellonian University in Kraków entirely devoted to African Studies, this time focusing on the problem of state dysfunctionality on the African continent in its different dimensions and shades.

In the second decade of the 21 st century, the world is still struggling with the problems of extreme poverty, economic and social underdevelopment, drastic cases of violations of human rights, armed conflicts, the problem of refugees, illiteracy or epidemics. They mainly affect about two billion people living in fewer than 40 countries with a high degree of state dysfunctionality. The most often quoted think-tank studying this phenomenon - the Fund for Peace (FFP) - in the 2018 edition of its Fragile States Index $(\mathrm{FSI})^{2}$ considered 35 states to experience a high degree of dysfunctionality; 26 of them were African states, which is 74 per cent of the total number of the most dysfunctional states in the world ${ }^{3}$. Moreover, 25 of them are Sub-Saharan African countries and among the top ten most dysfunctional states, according to the FSI 2018, seven are located in Sub-Saharan Africa: South Sudan (1), Somalia (2), Central African Republic (5), Democratic Republic of the Congo (6), Sudan (7), Chad (8), and Zimbabwe (10). Taking into account that in Sub-Saharan Africa there are 49 countries, representing 25 per cent of all the countries in the world, as well as the fact that Sub-Saharan Africa is home to more than a billion people, or 13.6 per cent of the world's population, it depicts how much this region is affected by the problem and how great its scale is ${ }^{4}$.

1 “Fragile States Index 2018", Fund for Peace, at <http://fundforpeace.org/fsi/data/>, 12 December 2018 .

2 In the years 2005-2013 the Index was known as Failed States Index.

3 “Fragile States Index 2018..." The only non-Sub-Saharan African state in this group of highly dysfunctional states is Libya.

4 "Population 2017", The World Bank, at <https://data.worldbank.org/indicator/SP.POP.TOTL ?end=2017\&locations=ZG\&start=2017\&view=bar >, 12 December 2018. 
The phenomenon of state dysfunctionality has been present in the global political reality since the beginning of state organisms and in the history there are many examples of states that failed to duly and effectively perform their functions. Nevertheless, only the beginning of the 1990s brought an increased interest in this phenomenon, at the time most often referred to as state failure. Initially, this problem was considered mainly in the context of the humanitarian situation of areas affected by statehood crisis, however, after the September 11 attacks, the securitization process of this phenomenon began and state dysfunctionality started to be included in the international security discourse and national security agendas.

It is a truism to say that a great diversity that characterizes the contemporary world also applies to dysfunctional states. State dysfunctionality depends on many factors, which in the case of African statehoods may be, for example, specific conditions for their historical development, different in relation to particular former European colonial powers. The state dysfunctionality on the African continent has many different shades, often presenting its own specificity in particular regions. Most researchers describing the problems of African countries, especially Sub-Saharan ones, point to such factors as the legacy of colonialism, bad governance, tribalism and group conflicts (mainly of ethnic character), economic underdevelopment, corruption or the economy based on natural resources (often referring to the concept of resource curse). However, the problem itself seems to be much more complex and it would be a mistake to tar the entire region in question with the same brush. The presented volume was intended, among other things, to embrace this diversity depicted in a number of case studies in which the contributors analyze some of the factors leading to state dysfunctionality in Africa, the situation in particular African states or regions, as well as the attempts undertaken to tackle this phenomenon.

In the first article of the volume, Robert Kłosowicz analyzes the problem of bad governance considered a determinant of state dysfunctionality in Sub-Saharan Africa. In the following article, Wiesław Lizak paints a picture of the current situation in Libya, taking into account a variety of factors leading to state dysfunctionality. Joanna Mormul tries to assess the role of Portuguese colonial legacy in Luso-African states, while Dominik Kopiński reflects upon the condition of statehood in Angola. Krzysztof Trzciński focuses on hybrid power-sharing used to stabilize political situation in multisegmental societies, drawing a comparison between the situation in Nigeria and Indonesia. Hanna Rubinkowska-Aniol introduces the readers to the Ethiopian Renaissance, its symbolical meaning and the ways it is being employed by Ethiopia's government. Emilia Bamwenda discusses the current shift towards the authoritarian state in Tanzania under the rule of President John P. Magufuli, while Andrzej Polus and Wojciech Tycholiz analyze the natural resource sector in Tanzania as an example of an extractive sector in Sub-Saharan functional state. Kateřina Rudincová explains the concept of African Solution to African Problems on the example of the AU and conflict resolution in South Sudan. Jakub Kościółek focuses on the use of R2P mechanism to deal with cases of serious human rights infringements in Africa. Katarzyna Wardin explains the correlation between armed conflicts in fragile states and illegal migrations and refugees 
in the European Union, drawing conclusions through the analysis of operations and missions in Libya and Somalia. Joanna Garlińska-Bielawska and Małgorzata Janicka discuss the presence of fragile states in African economic communities, using as an example the Economic and Monetary Community of Central Africa (CEMAC). Finally, in the last article in the volume, Anna Cichecka brings together political, economic and developmental aspects of the model of integration adopted by the East African Community (EAC), analyzed as a possible solution to the most important regional problems.

The variety of research subjects undertaken by the authors in this issue confirms a continous interest in the phenomenon of state dysfunctionality and its African exemplification. As an editor of this volume I would like to thank all the authors for their outstanding work. I strongly believe that their valuable contributions collected in this issue, together with their interdisciplinary approach, will provide the readers with a tool facilitating the understanding of such a multidimensional phenomenon as the problem of state dysfunctionality in Africa. 